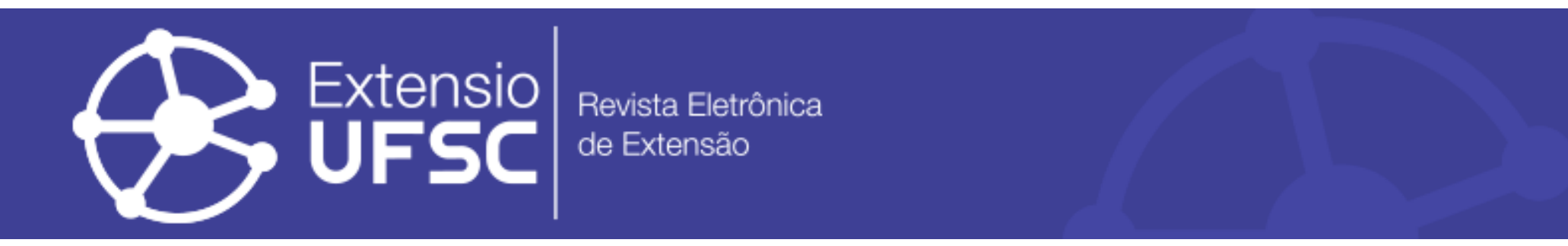

\title{
RELATO DE EXPERIÊNCIA: CAPACITAÇÃO EM PRIMEIROS SOCORROS DE ACADÊMICOS DO CURSO DE PEDAGOGIA
}

\author{
Kelly Aparecida Zanella \\ Universidade Federal da Fronteira Sul \\ kelly-zanella@live.com \\ Marizete Pigato Toldo \\ Universidade Federal da Fronteira Sul \\ marizetetoldo@hotmail.com
}

\author{
Fabrício Maas \\ Universidade Federal da Fronteira Sul \\ maas_fabricio@yahoo.com \\ Fabíola Feltrin \\ Universidade Estadual de Ponta Grossa \\ fabiolafeltrin@hotmail.com \\ Gelson Aguiar da Silva Moser \\ Universidade Federal da Fronteira Sul \\ gelson.silva@uffs.edu.br
}

\begin{abstract}
Resumo
Este trabalho discorre sobre um projeto, realizado durante os meses de agosto a dezembro de 2016, na Universidade Federal da Fronteira Sul - UFFS, que visou difundir o conhecimento sobre noções básicas de primeiros socorros para o curso de Graduação de Pedagogia e fortalecer o empoderamento dos acadêmicos envolvidos. Participaram do projeto oito acadêmicas da oitava fase do curso de pedagogia. Foram realizados, no total, seis encontros com aulas teóricas e práticas localizadas no campus oficial da UFFS. Ao final do projeto, foi realizada uma prova teórica com questões objetivas para avaliar a evolução de conhecimento das acadêmicas e um simulado para análise prática das mesmas. Nesta última prova, foi deixado um espaço para uma enquete de caráter dissertativo com intuito de um retorno avaliativo mais específico do projeto. Ao expandir o conhecimento deste assunto para a sociedade há, de certa forma, uma contribuição para a redução dos agravos à saúde. Estes conhecimentos, embasados cientificamente, poderão ajudar a salvar vidas.

Palavras Chave: Emergência. Enfermagem. Acidentes. Primeiros Socorros.
\end{abstract}

\section{EXPERIENCE REPORT: TRAINING IN THE FIRST AID OF ACADEMICS OF THE PEDAGOGY COURSE}

\begin{abstract}
This project aimed to disseminate knowledge about the basic first aid concepts for the Undergraduate Pedagogy course and to strengthen the empowerment of these academics. Eight students from the eighth phase of the pedagogy course participated in the project. A total of six meetings were held with theoretical and practical classes located at the official campus of the Federal University of the South Frontier (UFFS). At the end of the project, a theoretical test was carried out with objective questions to evaluate the evolution of the knowledge of the students and a simulation for their practical evaluation. In this last test, it was left a space for a poll of a dissertation character, in order to evaluate in a more specific way the project. By expanding the knowledge of this subject to society, there is in a way a contribution to the reduction of health problems. These scientifically grounded knowledge can help save lives. The project was carried out during the months of August to December of 2016.
\end{abstract}

Keywords: Emergency. Nursing. Accidents. First Aid.

\section{RELATO DE EXPERIENCIA: CAPACITACIÓN EN PRIMEROS AUXILIOS DE ACADÉMICOS DEL CURSO DE PEDAGOGÍA}

\section{Resumen}

Este proyecto apunta a difundir el conocimiento sobre las nociones básicas de primeros auxilios para el curso de Graduación de Pedagogía y fortalecer el empoderamiento de esos académicos. Participaron del proyecto ocho académicas de la octava fase del curso de pedagogía. Se realizaron el total de seis encuentros con clases teóricas y prácticas ubicadas en el campus oficial de la Universidad Federal de la Frontera Sur -UFFS. Al final del proyecto, se realizó una prueba teórica con cuestiones objetivas para evaluar la evolución de conocimiento de las académicas y un simulado para evaluación práctica de las mismas. En esta última prueba, se ha dejado un espacio para una encuesta de carácter disertivo, con el fin de evaluar de forma más específica el proyecto. Al expandir el conocimiento de este asunto a la sociedad, hay de cierta forma una contribución a la reducción de los agravios a la salud. Estos conocimientos, basados científicamente, pueden ayudar a salvar vidas. El proyecto fue realizado durante los meses de agosto a diciembre de 2016.

Palabras clave: Emergencia. Enfermería. Accidentes. Primeros Auxilios. 
Relato de experiência: capacitação em primeiros socorros de acadêmicos do curso de Pedagogia

\section{INTRODUÇÃO}

O ensino de primeiros socorros, embora de grande importância devido à quantidade de agravos à saúde que acontecem no nosso dia a dia, ainda é pouco disseminado. Por vezes, quando é levado a estudo, ocorre de forma superficial, gerando assim o desconhecimento e a insegurança por parte da população (NARDINO et al. 2012).

Podemos definir primeiros socorros como os cuidados imediatos que devem ser oferecidos rapidamente a uma pessoa, vítima de acidente ou de mal súbito, devido ao seu estado físico por em perigo sua vida. Sua finalidade é a de manter as funções vitais e evitar o agravamento de seu estado, empregando medidas e condutas até a chegada de assistência qualificada (FIOCRUZ, 2003).

Em situações de emergência, a falta de conhecimento da população em geral pode ocasionar vários problemas à recuperação da vítima, como o estado de pânico ao ver o acidentado, a manipulação incorreta dos mesmos ou excessivas solicitações desnecessárias de socorro especializado (NARDINO, 2012).

Neste sentido, existe a necessidade urgente de orientação educacional ao público leigo, procurando o despertar de mudanças comportamentais e noções básicas de primeiros socorros que possam colaborar para a diminuição de danos às vítimas, adequando conhecimentos suficientes para agirem como instrumentos na diminuição de acidentes e situações de emergência, minimizando assim os danos à saúde (NARDINO, 2012).

Uma das alternativas para que a população leiga adquira conhecimento sobre o assunto é o desenvolvimento de ações específicas sobre o tema a ser apresentado, desenvolvidas dentro das universidades, especificamente com projetos de extensão. Sendo assim, acredita-se que com um trabalho de empoderamento e sensibilização pode-se promover e desenvolver ações de saúde com ênfase nos primeiros socorros.

Como as crianças passam grande parte do dia nas escolas e realizam diversas atividades e brincadeiras, acidentes podem ocorrer. Nessas ocasiões, um professor, educador e/ou funcionário da escola com capacidade e noções sobre o primeiro atendimento em um evento adverso se faz imprescindível. Porém, não são repassados treinamentos adequados para socorrer vítimas destas situações e, por isso, os profissionais apresentam dificuldades no atendimento ou não sabem como proceder no momento do ocorrido (OLIVEIRA JUNIOR; SILVA JUNIOR; TOLEDO, 2013). 
Relato de experiência: capacitação em primeiros socorros de acadêmicos do curso de Pedagogia

O aprendizado em emergência, principalmente no ambiente escolar, determina que medidas precoces e de extrema importância sejam realizadas o mais rápido possível após o acidente, e com isso, complicações e sequelas à vítima serão amenizadas. Outro aspecto relevante é o fato de que com profissionais capacitados o ambiente torna-se mais seguro para a criança (CALAMDRIN et al., 2017).

Diante dessa realidade, o objetivo do presente projeto foi instrumentalizar acadêmicas de pedagogia da UFFS sobre noções básicas de primeiros socorros, buscando a construção de um conhecimento específico, crítico e reflexivo sobre o assunto abordado que as possibilitasse agir seguramente em situações de emergência, sem causar mais agravos à vítima. Em outras palavras, pretendeu-se difundir o conhecimento sobre as noções básicas de primeiros socorros dentro da comunidade acadêmica e fortalecer o empoderamento dos acadêmicos.

\section{METODOLOGIA}

Trata-se de um relato de experiência a partir de um projeto de extensão realizado com acadêmicas da oitava fase do curso de pedagogia da UFFS. O projeto surgiu a partir das acadêmicas do curso, devido à necessidade de conhecimentos sobre primeiros socorros. Após ter surgido essa demanda para o curso de enfermagem, ocorreu a formulação e envio do projeto para aprovação pelo departamento de extensão como projeto de livre demanda. Com a aprovação do mesmo, inicialmente foi oficializado o convite às acadêmicas e informado o prazo para a realização da inscrição.

O projeto teve a duração de cinco meses, com início em agosto de 2016 e atividades até dezembro do mesmo ano. As aulas foram realizadas no campus oficial da UFFS, sendo elas teóricas e práticas: primeiramente utilizando-se de recursos audiovisuais - através de slides - e em um segundo momento as aulas práticas de cada tópico proposto. Foram realizados seis encontros no total.

No primeiro encontro foram expostos os assuntos a serem abordados durante esse período, bem como maiores informações sobre algumas questões de interesse do público-alvo. Participaram inicialmente do projeto treze acadêmicas e, no final, o número de participantes foi de oito acadêmicas do curso de pedagogia. Visando melhor abordagem e entendimento sobre o nível de informação das integrantes sobre o tema, inicialmente foi realizada uma prova teórica com questões objetivas, avaliando desta forma, o conhecimento prévio das acadêmicas. $\mathrm{Na}$ sequência, as aulas foram administradas conforme cronograma. 
Relato de experiência: capacitação em primeiros socorros de acadêmicos do curso de Pedagogia

Os assuntos, abordados por acadêmicos do curso de graduação de Enfermagem da UFFS, foram os seguintes: Princípios Básicos de Biossegurança (Segurança do "Socorrista"); Sinais Vitais, prática e verificação; Engasgamento parcial/total (adulto/infantil/lactente) manobra de Heimlich; Fraturas, luxações e entorses; Queimaduras; Intoxicação (inalação, contato, ingestão e injeção); Convulsões; Parada Cardio Respiratória - PCR; Desmaios/ síncope; Choque elétrico; Hemorragias; Feridas fechadas e abertas; Cuidados com corpo estranho; Queda; Imobilização (curativos, uso de bandagens, ataduras, tala, etc).

Os encontros sempre eram realizados conforme disponibilidade das acadêmicas participantes, nos quais eram também retomados os temas anteriores, sanando possíveis dúvidas. Ao final do projeto foi realizada uma prova teórica com questões objetivas para avaliar a evolução de conhecimento das acadêmicas e um simulado para avaliação prática das mesmas. Nesta última foi deixado um espaço para uma enquete de caráter dissertativo, com intuito de possibilitar retornos avaliativos mais específicos do projeto, que serão expostos na discussão do presente trabalho: cada participante foi identificada pela letra (A) de Aluna e o número sequencial dos depoimentos, ou seja, A1 (Aluna 1) até a 8.

\section{RESULTADOS}

Conforme mencionado, a finalização do projeto contou com mais uma prova teórica de questões objetivas para avaliar a evolução de conhecimento das acadêmicas e um simulado para avaliação prática das mesmas. No término das atividades, foi disponibilizada certificação do projeto para as participantes que obtiveram frequência acima de $80 \%$.

Nesta última prova, foi deixado um espaço para uma enquete de caráter dissertativo, onde ficava a critério de cada aluna expor o que achou do projeto, sendo que não havia obrigatoriedade de identificação da participante. O intuito desse espaço era avaliar de forma mais específica o projeto: se, ao final, o objetivo do mesmo fora alcançado.

Para avaliar o resultado deste projeto, foram descritos alguns depoimentos das participantes:

A1: "O projeto é de extrema importância principalmente para nós que atuamos na educação, diretamente com crianças; estar minimamente preparada para estas situações faz toda diferença. As aulas ocorreram de forma didática, o que facilitou o entendimento”.

A2: "O projeto foi de grande importância para mim, pois os assuntos abordados são extremamente necessários para a vida pessoal e profissional de qualquer pessoa, ainda mais de um 
Relato de experiência: capacitação em primeiros socorros de acadêmicos do curso de Pedagogia

professor; uma forma bem didática e ao mesmo tempo descontraída de aprender. Todos os pedagogos e ou qualquer outro profissional teriam que ter esse curso".

A3: "O projeto nos possibilitou um conhecimento importante para ser usado em caso de acidentes que acontecem no dia a dia. Saber fazer o procedimento correto é essencial quando se trata de salvar vidas e esse curso foi de grande aproveitamento nessa questão, onde tivemos não só a teoria, mas aulas práticas para melhor entendimento. Acredito que este projeto deve continuar para que mais pessoas possam ter esse conhecimento, ter a noção de primeiros socorros: para mim foi um curso muito proveitoso".

A4: "Bom, então: o projeto de Primeiros Socorros foi uma iniciativa que deu certo, que foi muito válido e construtivo para todos. E que mais projetos envolvendo a saúde deveriam ser desenvolvidos para se trabalhar com os outros cursos, porque ninguém está livre de se deparar com alguma situação algum dia que vá exigir de nós conhecimentos sobre primeiros socorros, ou que exija outros conhecimentos".

A5: "Com certeza as horas que passamos em curso com as acadêmicas da enfermagem foram de suma importância para minha vida profissional e também pessoal. Aprendi na teoria e na prática o que fazer em caso de emergência. Tudo foi muito valioso nas aulas. Sempre me senti segura pois pude perceber que todos tinham domínio e clareza sobre o que estavam ensinando. Entrei leiga no curso e sei que consegui ampliar meu conhecimento no assunto. Sem mais palavras, o curso foi muito satisfatório".

Para avaliação do conhecimento das acadêmicas foram realizadas duas provas teóricas, com dez questões objetivas. A primeira prova foi aplicada no primeiro encontro para examinar o nível de conhecimento das acadêmicas. Ao final, no último encontro, foi aplicada a mesma prova para mensurar a evolução de aprendizado das discentes.

\section{DISCUSSÃO}

Pode-se perceber através dos depoimentos acima mencionados, que pessoas devidamente orientadas/qualificadas são de fato capazes de prevenir acidentes e de agir adequadamente evitando maiores sequelas nas emergências que por ventura venham a ocorrer. Entretanto, apesar de sua relevância devido à grande prevalência de agravos à saúde observáveis diariamente no trânsito, nas escolas ou em casa, o ensino de primeiros socorros ainda é pouco difundido entre a população em geral.

De acordo com Veronese et al. (2010) o aprendizado de primeiros socorros se restringe basicamente aos profissionais de saúde ou aqueles que estão próximos de universidades, hospitais 
Relato de experiência: capacitação em primeiros socorros de acadêmicos do curso de Pedagogia

e de outros centros que promovam tais cursos. Neste cenário, muitas profissões acabam ficando despreparadas para enfrentar situações de risco à vida.

Profissionais da educação, muitas vezes, são mal preparados para lidar com os possíveis acidentes. A graduação apresenta déficit de conhecimento nesse ramo ou, quando apresenta, é de forma insuficiente: o que resulta em educadores com pouca capacidade ou nenhuma para atuar em situações de emergência e prestar os primeiros socorros (ESTEVES et al., 2015).

Sabe-se que em fases educacionais, as crianças e os jovens permanecem no ambiente escolar, nas instituições de ensino, grande parte do seu dia e da vida. Nesse período, os alunos estão sob responsabilidade dos professores - sendo aptos ou não, cabe a eles protegê-los com total dedicação em relação à segurança (CARVALHO, 2014). Logo, torna-se evidente a importância do ensino de primeiros socorros aos profissionais que lidam com crianças no seu cotidiano - em especial no ambiente escolar onde é muito comum a ocorrência de eventos adversos.

Segundo Carvalho (2014), os casos mais frequentes de acidentes no ambiente escolar são: fraturas, luxação, obstrução de vias aéreas, crise convulsiva, sangramento, queimaduras, ferimentos, parada cardiorrespiratória e desmaios. Professores e funcionários devem, portanto, estar aptos a tomar as medidas cabíveis em casos de acidentes, além de tentar ao máximo evitar que eles ocorram.

Com o conhecimento adequado, professores, colaboradores da escola, e inclusive os próprios estudantes, podem agir de forma apropriada e tomar iniciativas diante de situações emergenciais que possam ocorrer no ambiente escolar e fora dele. Esses, aplicando técnicas adequadas, podem proporcionar condições seguras até a chegada do socorro especializado.

É imprescindível que professores, como potenciais responsáveis pela segurança dos estudantes, tenham acesso às informações de primeiros socorros, com material educativo visando ampliar o conhecimento sobre os principais acidentes. Os professores devem estar preparados, saber o que fazer e como proceder frente às situações que exijam cuidados imediatos, evitando complicações decorrentes das medidas inadequadas em relação aos acidentes (LEMOS, 2011; PATRÍCIO, 2013).

A escola tem um papel fundamental na promoção da saúde, prevenção de doenças e acidentes entre os estudantes. Entretanto, para que isso aconteça, profissionais capacitados necessitam estar presentes diariamente nas escolas. Os mesmos também deveriam participar das atividades educativas como forma de explorar a potencialidade dos envolvidos (BOAVENTURA et al., 2011). 
Relato de experiência: capacitação em primeiros socorros de acadêmicos do curso de Pedagogia

\section{CONCLUSÃO}

No decorrer desta ação de extensão, as expectativas de repassar conhecimento atualizado para discentes do curso de pedagogia em relação às noções de primeiros socorros foram alcançadas. Isso contribuiu para reduzir ou minimizar acidentes ou lesões que poderiam ser maiores ou irreversíveis.

Ao expandir o conhecimento sobre este assunto para a sociedade, de certa forma, há uma contribuição para a redução dos agravos à saúde com procedimentos simples, os quais foram agrupados e revisados durante toda realização do projeto. Estes conhecimentos, embasados cientificamente, poderão ajudar a salvar vidas pois em momentos de emergência, saber fazer a coisa certa, eficazmente, mantendo a calma e o controle da situação, permite que a vítima aguarde o socorro especializado em segurança.

O projeto foi muito valioso em relação à participação e avaliação por parte das acadêmicas participantes. Os assuntos abordados contribuíram para uma melhor formação dos futuros profissionais do curso de pedagogia e isso só reafirma a importância de termos profissionais capacitados em primeiros socorros dentro das escolas.

As acadêmicas puderam assimilar o conteúdo repassado nos encontros, conforme observado nos resultados das avaliações realizadas antes e depois das atividades teóricas e práticas. Tais profissionais poderão fazer a diferença no mercado de trabalho, passando segurança para as famílias das crianças e até mesmo fazendo a diferença no cotidiano fora do ambiente escolar em uma situação necessária de urgência e emergência.

\section{REFERÊNCIAS}

BOAVENTURA, Ana Paula et al. Primeiros socorros no ambiente escolar relato de experiência na divisão de educação infantil e complementar da universidade estadual de campinas. Revista Saberes Universitários, Campinas, v. 2, n. 2, p.147-158, set. 2017. Disponível em: <http://www.sbu.unicamp.br/seer/ojs/index.php/saberes/article/view/7596/4556>. Acesso em: 25 out. 2017.

CALANDRIM, Lucas Felix et al. Primeiros socorros na escola: treinamento de professores e funcionários. Revista Rene, Campinas, v. 3, n. 18, p.292-299, maio 2017. Disponível em: <http://periodicos.ufc.br/rene/article/view/20044>. Acesso em: 25 out. 2017.

CARVALHO, Luana Silveira et al. A Abordagem de Primeiros Socorros Realizada Pelos Professores em uma Unidade de Ensino Estadual em Anápolis - GO. Ensaios e Ciência: 
Relato de experiência: capacitação em primeiros socorros de acadêmicos do curso de Pedagogia

Biológicas, Agrárias e da Saúde, Anápolis, v. 18, n. 1, p.25-30, 2014. Disponível em: <http://www.redalyc.org/articulo.oa?id=26037787004>. Acesso em: 17 jul. 2017.

ESTEVES, Dulce et al. Avaliação do conhecimento dos professores de educação física para reagirem a situações de emergência. Revista Motricidade, Ribeira de Pena- Portugal, v. 1, n. 11, p.39-52, 2015. Disponível em: < http://revistas.rcaap.pt/motricidade/article/view/3125/5153>. Acesso em: 25 out. 2017.

FIOCRUZ, Fundação Oswaldo Cruz. Manual de Primeiros Socorros. Rio de Janeiro: Ministério da Saúde Fundação Oswaldo Cruz - Fiocruz, 2003. 170 p. Disponível em: $<$ http://www.fiocruz.br/biosseguranca/Bis/manuais/biosseguranca/manualdeprimeirossocorros >. Acesso em: 17 jul. 2017.

LEMOS et al. Educação em saúde: a experiência de alunos de Medicina no ensino em primeiros socorros. Revista participação n. 20 (2011) Disponível em: http://periodicos.unb.br/index.php/participacao/article/view/6392/5901 Acesso em: 24 out. 2017.

MATOS, Diana Oliveira do Nascimento; SOUZA, Ruth Soares de; ALVES, Shirlei Marly. Inclusão da disciplina de primeiros socorros para alunos do ensino básico. Revista

Interdiciplinar, Piauí, v. 9, n. 3, p.168-178, 07 mar. 2016. Disponível em: $<$ http://revistainterdisciplinar.uninovafapi.edu.br/index.php/revinter/article/view/923/pdf_354 >. Acesso em: 17 jul. 2017.

NARDINO, Janaine et al. Atividades educativas em primeiros socorros. Revista Contexto \&sa;úde Ijuí., Ijuí, v. 12, n. 23, p.88-92, 2012. Julho A Dezembro. Disponível em: $<$ https://www.revistas.unijui.edu.br/index.php/contextoesaude/article/download/.../2545>. Acesso em: 03 ago. 2016.

OLIVEIRA JÚNIOR, Miguel A. de; SILVA JÚNIOR, Carlos Jaime da; TOLEDO, Elizandra Maria de. O Conhecimento em Pronto-Socorrismo de Professores da Rede Municipal de Ensino do Ciclo I de Cruzeiro-SP. Educação, Cultura e Comunicação, São Paulo, v. 4, n. 7, p.39-48, 01 jun. 2013. Disponível em:

<http://publicacoes.fatea.br/index.php/eccom/article/view/591>. Acesso em: 15 jul. 2017.

PATRÍCIO, Anna Cláudia Freire Araújo et al. Conhecimento dos profissionais que trabalham na educação infantil: prevenção e manejo do trauma. Revista Enfermagem Ufpe On Line, Recife, p.6617-6623, nov. 2013. Disponível em:

<https://periodicos.ufpe.br/revistas/revistaenfermagem/article/download/12316/15007>. Acesso em: 24 out. 2017.

VERONESE, Andréa Márian et al. Oficinas de primeiros socorros: relato de experiência. Revista Gaucha de Enfermagem, Porto Alegre, v. 31, n. 1, p.179-182, mar. 2010. Disponível em: <http://www.scielo.br/scielo.php?script=sci_arttext\&pid=S198314472010000100025>. Acesso em: 03 ago. 2016.

Recebido em: 07/11/2017

Aceito em: 26/11/2018 